Gut, 1976, 17, 536-541

\title{
Effect of gastrin on gastric mucosal cell proliferation in man
}

\author{
O. HART HANSEN, ${ }^{1}$ T. PEDERSEN, J. K. LARSEN, AND J. F. REHFELD \\ From the Departments of Surgery $A$ and Clinical Chemistry, Bispebjerg Hospital, and The Finsen \\ Laboratory, The Finsen Institute, Copenhagen, Denmark
}

SUMMARY The effect of short-term infusion of a large dose of pentagastrin and a small dose of synthetic human gastrin I (SHG) on the rate of cell proliferation in gastric mucosa was studied in normal human subjects. Moreover, the kinetic parameters were compared with the serum gastrin concentrations in fasting patients. Endoscopic biopsies were labelled in vitro with ${ }^{3} \mathrm{H}$-thymidine and autoradiographs were prepared. The percentage of DNA-synthesising cells in the progenitor cell region was estimated. In healthy volunteers infusion of a large dose of pentagastrin $(10 \mu \mathrm{g} / \mathrm{kg}$ per hour) was followed by a marked increase in the labelling index in fundic mucosa. The antral mucosa was not responsive to this effect. In the same subjects, infusion of a low dose of SHG $(8 \mathrm{ng} / \mathrm{kg}$ per min) did not affect the rate of cell proliferation, either in fundic or in antral mucosa. In 46 patients with different gastric diseases no correlation between the serum gastrin concentrations and the labelling indices was found. The results suggest that human fundic mucosa is responsive to a trophic action of pentagastrin. If it exists, however, a physiological action of gastrin as a trophic hormone for human gastric mucosa must be considerably more complex than previously believed.

In 1969 Johnson and his colleagues hypothesized that gastrin was a trophic hormone for certain tissues of the gastrointestinal tract including gastric mucosa. Since then the hypothesis has been supported by a number of experimental investigations. Chronic administration of pentagastrin produces parietal cell hyperplasia in rats (Crean et al., 1969; Stanley et al., 1972), and injections of pentagastrin have been demonstrated to stimulate protein (Johnson et al, 1969; Sutton and Donaldson, 1975), RNA (Chandler and Johnson, 1972), and DNA (Johnson and Guthrie, 1974) synthesis in gastric and duodenal mucosa. Willems et al. (1972) have shown that continuous infusion of porcine gastrin for four hours was followed by a significant increase in the labelling and mitotic indices in canine fundic mucosa. By contrast no increase in DNA-synthesis and in the mitotic index appeared after infusion of histamine. These results all indicated that gastrin has a trophic influence on rat and dog gastric mucosa. However, the conclusions may not necessarily be valid for man. Miller et al. (1973) found that pentagastrin inhibited fibroblast growth and promoted the pro-

${ }^{1}$ Address for correspondence: Dr O. Hart Hansen, Bispebjerg Bakke 33, DK-2400 Copenhagen NV, Denmark.

Received for publication 19 February 1976 liferation of epithelial cells in cultures of human gastric mucosa from the oxyntic gland region, but no further studies on the trophic action of gastrin have been performed on human tissue.

The purpose of this study was (1) to investigate the effect of exogenous gastrin on cell proliferation kinetics in normal human gastric mucosa, and (2) to determine the relationship between the kinetic parameters and the serum gastrin concentrations in a series of patients with different gastric diseases.

\section{Methods}

\section{SUBJECTS}

After informed consent one female and two male healthy volunteers aged 27,21 , and 26 years were studied. In all three subjects the stomach was normal by endoscopic and histological examination. Gastroscopy was performed using a fibreoptic gastroscope (Olympus GIF-K). The only premedication utilized was a pharyngeal spray (Leostesin). Through the gastroscope biopsies were taken from the lesser curvature in the antral part of the stomach and from the greater curvature in the fundic part in each examination, carefully avoiding previous biopsy sites. Histologically, the biopsies included mucosa to the 
level of the lamina of the muscularis mucosae.

INVESTIGATIVE PROCEDURE

1. In the three subjects biopsies were taken after 12 hours fasting. Immediately after the gastroscopy, pentagastrin (Peptavlon, Imperial Chemical Industries, Cheshire) was given intravenously as a 120 minute infusion of $10 \mu \mathrm{g} / \mathrm{kg}$ per hour. Sixteen hours after starting the infusion endoscopic biopsies were again obtained.

2. In another study in the same volunteers, biopsies were taken after 12 hours fasting. After the gastroscopy, synthetic human gastrin (SHG I, Imperial Chemical Industries, Cheshire) was given intravenously as a 150 minute infusion of $8 \mathrm{ng} / \mathrm{kg}$ per minute. Biopsies were again taken eight, 16, and 24 hours after starting administration of SHG. Blood samples for measurements of serum gastrin concentrations were drawn before, 45 and 135 minutes after the onset of infusion. The two experiments were performed with an interval of three months.

3. In a third study, 46 randomly selected patients with different gastric diseases (Table) were investigated. There were 27 women and 19 men with ages ranging from 21 to 81 years. Gastroscopy was performed after an overnight fast and biopsies were taken as described above. All the biopsies were obtained from non-diseased areas of the stomach. Immediately before the endoscopic examination blood samples were drawn for measurements of serum gastrin concentrations.

Table Endoscopic diagnosis in 46 patients studied

\begin{tabular}{lc}
\hline Diagnosis & Number of patients \\
\hline Normal stomach & 13 \\
Duodenal ulcer & 7 \\
Prepyloric ulcer & 5 \\
Gastric ulcer & 6 \\
Gastric cancer & 5 \\
Atrophic gastritis & 10 \\
\hline
\end{tabular}

\section{Autoradiographic procedure}

The biopsies were immediately incubated in a shaking water bath at $37^{\circ} \mathrm{C}$, in $5 \mathrm{ml}$ of Eagle's basal medium with Hanks' salts (Flow Laboratories, Rockville, USA) containing $20 \mu \mathrm{Ci}$ per $\mathrm{ml}$ of ${ }^{3} \mathrm{H}$ thymidine (Radiochemical Centre, Amersham, of specific activity $25 \mathrm{Ci}$ per mmol). The $\mathrm{pH}$ was adjusted to 7,3-7,4 with sodium bicarbonate. After incubation for 30 minutes, the specimens were washed in unlabelled medium for $\mathbf{1 0}$ minutes, fixed in Bouin's solution for one hour, embedded in paraffin, and serially sectioned at $4 \mu$. The slides were coated with liquid photographic emulsion (Ilford K2), exposed for two weeks at $4^{\circ} \mathrm{C}$, developed and stained with haematoxylin and eosin.
In the autoradiographs the background labelling was random and low, rarely exceeding 1 grain per $100 \mu^{2}$. The cells were considered labelled if they had five or more grains over the nucleus. The number of labelled cells as well as the total number of cells in all cross-sections of foveolae containing one or more labelled cells were counted blindly. Every third section of the serially sectioned biopsy material was surveyed. Using this counting procedure, cell counts were performed through the whole progenitor zone, both in antral and fundic mucosa. In each biopsy a minimum of 1000 cells were counted, and the percentage of labelled cells (LI) was estimated.

When only cross-sections containing labelled cells are taken into consideration, the LI will be overestimated because those cross-sections through the progenitor cell region, which do not have labelled cells, will not be included in the estimation of the LI. This error was reduced by use of a previously described equation for correction (Hansen et al., 1975). All the labelling indices reported in this paper are the corrected values.

\section{Serum gastrin concentrations}

These were measured radioimmunochemically using antiserum 2604-8 raised against SHG I. The binding sites of this antiserum are mainly directed against the biologically active C-terminal sequence of SHG. Although the antiserum is able to bind the synthetic analoque pentagastrin, the binding energy of this reaction is so weak (Rehfeld et al., 1972) that pentagastrin in serum cannot be measured after administration in doses like those in the present study. In contrast all the three large main components in serum (Rehfeld et al., 1974) are bound with a potency equal to SHG on a molar basis (Rehfeld et al., 1975). Monoiodinated SHG was used as tracer (Stadil and Rehfeld, 1972) and SHG as standard. Reliability criteria of the actual assay have been published in detail previously (Rehfeld and Stadil, 1973).

\section{STATISTICAL ANALYSIS}

The data obtained in the experiments with infusion of SHG have been analysed according to the method of analysis of variance. The difference either between the average response at each time interval and the results in the antral and fundic mucosa were tested. For statistical evaluation of the relationship between labelling indices and serum gastrin concentrations the Spearman coefficient of correlation ( $r$ SP) was calculated.

\section{Results}

Infusion of pentagastrin resulted in a marked increase in the labelling indices in fundic mucosa 16 
hours after starting the infusion (Fig. 1). In the antral specimens there were no significant changes in the labelling indices, but the values were slightly decreased in two of the subjects (Fig. 2). At gastroscopy 16 hours after the start of stimulation with pentagastrin, the development of a moderate, diffuse,

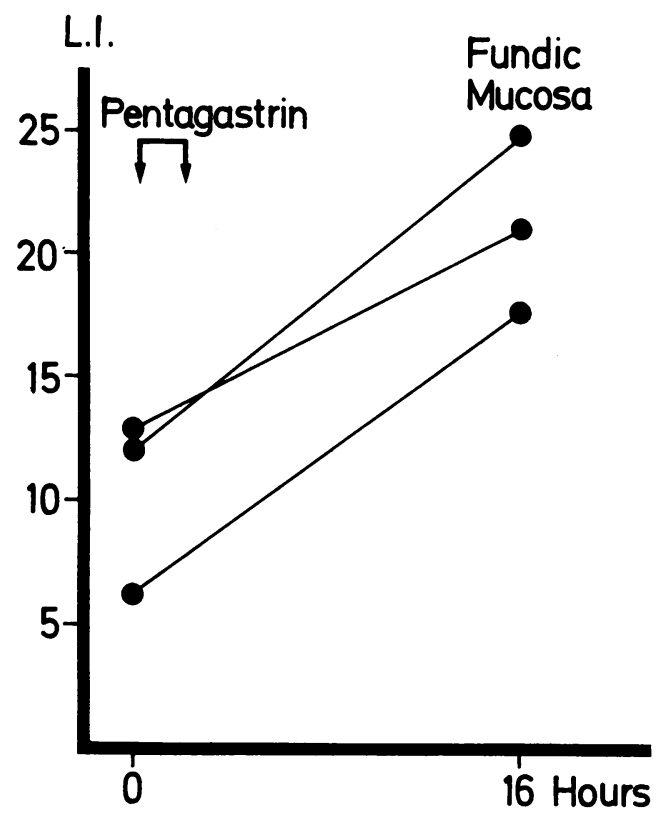

Fig. 1 Labelling index in fundic mucosa from three healthy subjects, before and 16 hours after intravenous infusion of pentagastrin $(10 \mu \mathrm{g} / \mathrm{kg}$ per hour $)$.

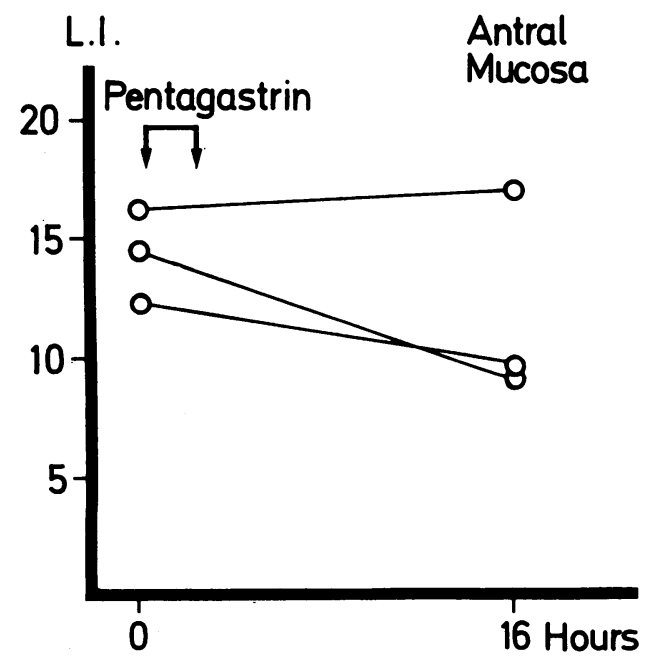

Fig. 2 Labelling index in antral mucosa from three healthy subjects, before and 16 hours after intravenous infusion of pentagastrin (10 $\mu \mathrm{g} / \mathrm{kg}$ per hour). acute gastritis was noted in all three volunteers. Histological examination of the biopsies obtained at this time showed a slight superficial gastritis, both in antral and fundic mucosa.

The increase in serum gastrin concentrations after infusion of SHG (Fig. 3) was about five times that of a physiological response to a protein-rich meal (Rehfeld and Stadil, 1973). During this experiment the gastric mucosa appeared completely normal at all the endoscopic examinations. The administration of SHG had no significant effect on the labelling indices, either in fundic or in antral mucosa (Fig. 3). The statistical analysis showed that the labelling indices were significantly higher in antral than in fundic mucosa during the whole study period $(\mathrm{P}<$ 0.01).
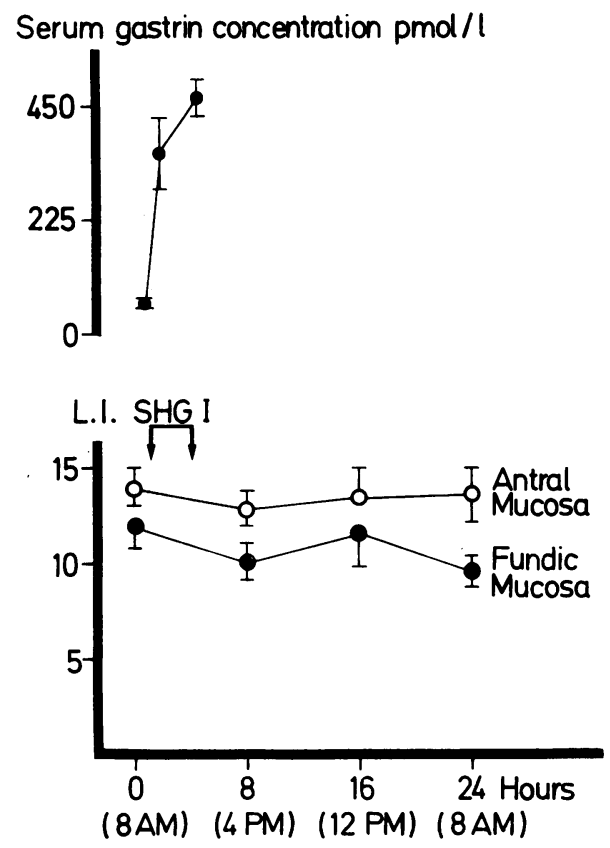

Fig. 3 Mean labelling index in antral and fundic mucosa from three healthy subjects, before and eight 16 , and 24 hours after intravenous infusion of SHG (8 $\mathrm{ng} / \mathrm{kg}$ per $\mathrm{min}$ ). Serum gastrin concentrations were measured before and during the infusion. Vertical bars indicate one $S E$.

As shown in Fig. 4, there was no correlation in $\mathbf{4 6}$ patients between the labelling indices in fundic mucosa and the basal serum gastrin concentrations. The results obtained from the studies of antral mucosa in 43 patients are shown in Fig. 5. In the three remaining cases the antral specimens were not suitable for study. Also, there was no correlation between serum gastrin levels and the labelling indices in the antral part of the stomach. 


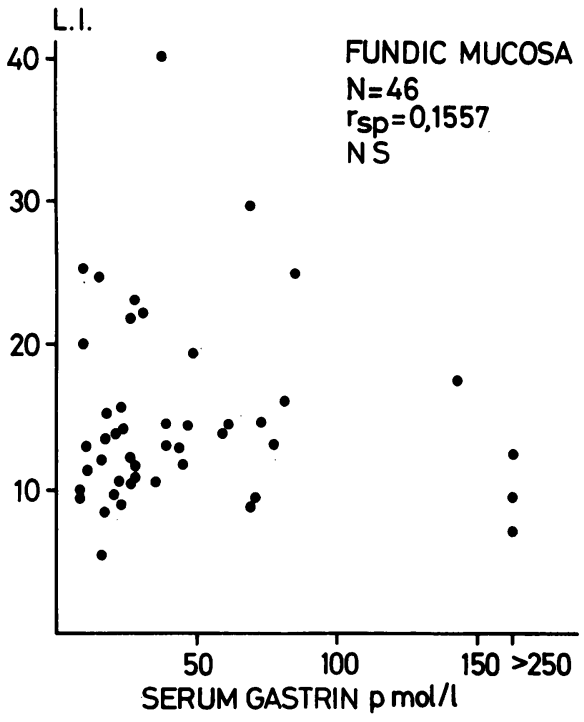

Fig. 4 Correlation between the labelling index in fundic mucosa and basal serum gastrin concentration in 46 patients.

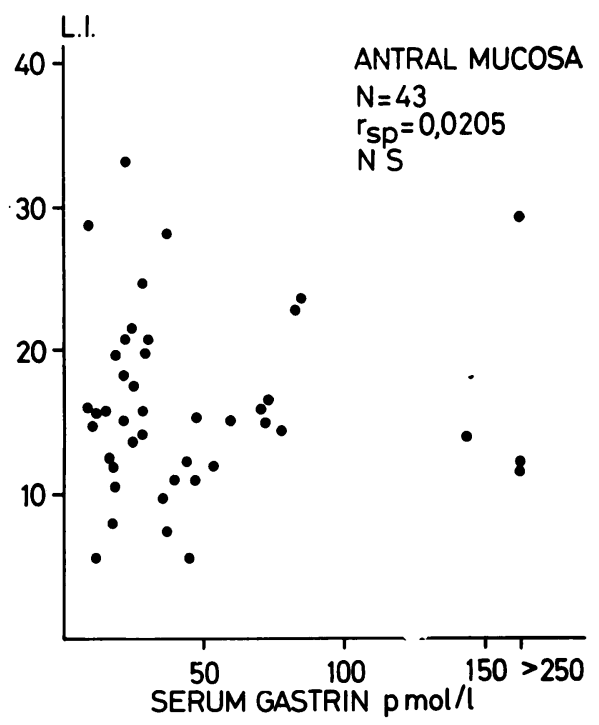

Fig. 5 Correlation between the labelling index in antral mucosa and basal serum gastrin concentration in 43 patients.

\section{Discussion}

The results of the present studies indicate that: (1) a large dose of pentagastrin does stimulate the rate of cell proliferation in human gastric fundic mucosa; (2) human antral mucosa is not responsive to the trophic action of pentagastrin; (3) a short-term in- fusion of a near physiological dose of SHG does not affect the rate of cell proliferation in human fundic and antral mucosa; and (4) there is no correlation between the basal serum gastrin concentration and the labelling index in human fundic and antral mucosa.

The technique of in vitro labelling with ${ }^{3} \mathrm{H}$ thymidine of endoscopic biopsies in combination with autoradiography has been found useful in studying cell proliferation kinetics in human gastric mucosa (Hansen et al., 1975). Using this technique no significant diurnal variations in the labelling and mitotic indices in normal human gastric mucosa were observed (Hansen et al., 1976). The absence of circadian variations suggests that the progenitor cell population is asynchronous, and thus the LI is approximately proportional to the growth rate of the cell population, under the assumption that the duration of the DNA synthetic phase does not differ in the subjects studied. The method seems well suited for the study of the effect of gastrin on the rate of cell proliferation in human gastric mucosa, and a similar in vitro method has been used to demonstrate a trophic action of gastrin in dog fundic mucosa (Willems et al., 1972).

In the present study, infusion of a high dose of pentagastrin elicited a trophic response by the marked increase in the DNA-synthesis index in fundic mucosa. This observation is in accord with investigations on rats and dogs where injections of pentagastrin and porcine gastrin resulted in a peak increase in DNA synthesis 16 hours later (Johnson and Guthrie, 1974a; Willems et al., 1972). In the animals the maximum uptake of ${ }^{3} \mathrm{H}$-thymidine was 200 to $300 \%$ of control values, while in man the labelling indices increased about $100 \%$. This difference may be attributed to species differences, but it is more likely that the peak increase in man was not reached after 16 hours, but occurred some time later. This could have been elucidated by taking a series of biopsies with short intervals after the administration of pentagastrin. Unfortunately, the possibilities of taking serial biopsies in the volunteers were limited. In the human antral mucosa, infusion of pentagastrin had no stimulating effect on the rate of cell proliferation. Similarly dog antral mucosa was not responsive to the trophic effect of gastrin (Willems and Vansteenkiste, 1974). The finding that antral and fundic mucosa reacts in different ways to the same stimulus indicates a different growth pattern which, to some extent, explains the lack of correlation between the rate of cell proliferation in antral and fundic mucosa from patients with different gastric diseases (Hansen et al., 1975).

Miller et al. (1973) showed that epithelial cells originating from human oxyntic gland mucosa can 
be grown in tissue culture and that pentagastrin is required to maintain the epithelial characteristics of that growth. This finding indicates that the trophic effects of pentagastrin observed in the present study resulted from a direct action of the hormone on the progenitor cells. However, stimulation with pentagastrin was followed by the development of acute gastritis in all three volunteers, and in gastritis the rate of cell proliferation is increased (Hansen $e t$ al., 1974). In large doses pentagastrin dilates gastric submucosal arterioles (Guth and Smith, 1975). and it is possible that the increased labelling indices after pentagastrin resulted from this effect together with the development of gastritis. As in other reports (Johnson, 1975) the present results were obtained after stimulation with pentagastrin, which is a synthetic, unphysiological drug. The physiological relevance to man of the trophic effects of gastrin is not clear.

The demonstration of atrophic gastritis and decreased thickness of the gastric mucosal remnant after antrectomy for peptic ulcer (Lees and Grandjean, 1958; Melrose et al., 1964) has led to the assumption that the hypotrophy is due to decreased amounts of circulating gastrin, and has been interpreted as presumptive evidence of physiological trophic activity of the hormone in man. However, it is not possible to find kinetic data supporting this hypothesis. In patients with duodenal ulcer the proliferative activity in gastric mucosa was found to be low, both by measurements of the rate of gastric DNA loss (Boyes et al., 1971) and in autoradiographic studies (Hansen et al., 1975). On the contrary, simple atrophic gastritis is associated with increased rates of cell proliferation (Boyes $e t$ al., 1971; Croft and Cotton, 1973; Steenbeck and Wolff, 1971), and in a preliminary study we found a high cell production rate in the gastric mucosal remnant after antrectomy (unpublished data). These findings suggest that the development of mucosal hypotrophy and atrophic gastritis after antrectomy in man is not simply caused by a decreased rate of cell renewal. Thus it is not possible to draw any conclusions concerning a trophic action of gastrin on basis of the mucosal changes after antrectomy.

In fasting dogs, food ingestion was followed by a significant increase in DNA synthesis in fundic mucosa, both in the intact stomach (Willems et al., 1971) and in Heidenhain pouches (Willems et al., 1972), indicating that gastrin, or some other humoral factor, had mediated the proliferative response. In rats, antrectomy resulted in decreases in RNA and DNA content of the duodenum and stomach (Johnson and Chandler, 1973) and in an overall reduction in the size of the fundic mucosa (Martin $e t$ al., 1970). The changes in nucleic acid content could be antagonized by a series of pentagastrin injections (Johnson and Chandler, 1973). These observations in animals are strong evidence that endogenous gastrin has a physiolgical function as a trophic hormone, which seems to be necessary for maintenance of the structural and functional integrity of the gastrointestinal tract (Johnson, 1975). However, neither ingestion of a protein rich meal (Hansen et al., 1976) nor infusion of a near physiological dose of SHG affected the rate of cell proliferation in human antral and fundic mucosa. Moreover, the lack of correlation between serum gastrin concentrations and the labelling indices in $\mathbf{4 6}$ patients, may indicate that the physiological action of gastrin as a trophic hormone for human gastric mucosa is limited.

The observation that short-term infusion of SHG had no effect on the rate of cell proliferation does not completely disprove the hypothesis, since a prolonged administration of gastrin might have resulted in a trophic response. It is possible that gastrin is an important part of the mechanisms regulating the growth of human gastric epithelium, but this mechanism seems to be as complex as that regulating gastric acid secretion. A significant inverse correlation between the rate of cell proliferation in human gastric mucosa and the augmented histamine response has been demonstrated (Pedersen et al., 1973), and it can be speculated that the same humoral factors are involved in regulation of both acid secretion and mucosal growth. Secretin, which has been shown to inhibit the trophic effect of gastrin on rat gastric mucosa (Johnson and Guthrie, 1974b), may be such a factor. If it exists, however, a physiological effect of gastrin on the rate of cell proliferation in human gastric mucosa must be considerably more complex than initially believed.

The technical assistance of Lars Bo Svendsen and Ulla Soegaard is gratefully acknowledged. The study was supported by The Danish Medical Research Council j. nr. 512-2540 and 512-2636.

\section{References}

Boyes, B. E., Crean, G. P., and Watkinson, G. (1971). Studies in the rates of epithelial cell exfoliation from the gastric mucosa in normal and in ulcer subjects. Gut, 12, 867.

Chandler, A. M., and Johnson, L. R. (1972). Pentagastrinstimulated incorporation of ${ }^{14} \mathrm{C}$-orotic acid into RNA of gastric and duodenal mucosa. Proceedings of the Society for Experimental Biology and Medicine, 141, 110-113.

Crean, G. P., Marshall, M. W., and Rumsey, R. D. E. (1969). Parietal cell hyperplasia induced by the administration of pentagastrin (ICI 50,123) to rats. Gastroenterology, 57, 147-155.

Croft, D. N., and Cotton, P. B. (1973). Gastro-intestinal cell loss in man. Digestion, 8, 144-160.

Guth, P. H, and Smith, E. (1975). The effect of gastro- 
intestinal hormones on the gastric microcirculation. Gastroenterology, 68, 907.

Hansen, O. H., Pedersen, T., and Larsen, J. K. (1975). A method to study cell proliferation kinetics in human gastric mucosa. Gut, 16, 23-27.

Hansen, O. H., Pedersen, T., and Larsen, J. K. (1976). Cell proliferation kinetics in normal human gastric mucosa: studies in diurnal fluctuations and effect of food ingestion. Gastroenterology, 70, 1051-1054.

Hansen, O. H., Pedersen, T., Larsen, J. K., and Johansen, Aa. (1974). The correlation between cell proliferation kinetics and histology in human gastric mucosa. In $V$ World Congress of Gastroenterology, p. 152, Abstracts, Mexico.

Johnson, L. R. (1975). Trophic action of gastrointestinal hormones. In Gastrointestinal Hormones, pp. 215-230. Edited by J. C. Thompson. University of Texas at Austin Press.

Johnson, L. R., Aures, D., and Yuen, L. (1969). Pentagastrin-induced stimulation of protein synthesis in the gastrointestinal tract. American Journal of Physiology, 217, 251-254.

Johnson, L. R., and Chandler, A. M. (1973). RNA and DNA of gastric and duodenal mucosa in antrectomized and gastrin-treated rats. American Journal of Physiology, 224, 937-940.

Johnson, L. R., and Guthrie, P. D. (1974a). Mucosal DNA synthesis: a short term index of the trophic action of gastrin. Gastroenterology, 67, 453-459.

Johnson, L. R., and Guthrie, P. D. (1974b). Secretin inhibition of gastrin-stimulated deoxyribonucleic acid synthesis. Gastroenterology, 67, 601-606.

Lees, F., and Grandjean, L. C. (1958). The gastric and jejunal mucosa in healthy patients with partial gastrectomy. Archives of Internal Medicine, 101, 943-951.

Martin, F., Macleod, I. B., and Sircus, W. (1970). Effects of antrectomy on the fundic mucosa of the rat. Gastroenterology, 59, 437-444.

Melrose, A. G., Russell, R. I., and Dick, A. (1964). Gastric mucosal structure and function after vagotomy. Gut, 5, 546-549.

Miller, L. R., Jacobson, E. D., and Johnson, L. R. (1973). Effect of pentagastrin on gastric mucosal cells grown in tissue culture. Gastroenterology, 64, 254-267.

Pedersen, T., Hansen, O. H., Larsen, J., and Christiansen, P. M. (1973). Cell kinetics of human gastric mucosa and its correlation to gastric acid secretion and serum gastrin level. (Abstract). European Journal of Clinical Investigation, 3, 261.

Rehfeld, J. F., and Stadil, F. (1973). The effect of gastrin on basal- and glucose-stimulated insulin secretion in man. Journal of Clinical Investigation, 52, 1415-1426.

Rehfeld, J. F., Stadil, F., Malmström, J., and Miyata, M. (1975). Gastrin heterogeneity in serum and tissue. In Gastrointestinal Hormones, pp. 43-58. Edited by J. C. Thompson. University of Texas at Austin Press.

Rehfeld, J. F., Stadil, F., and Rubin, B. (1972). Production and evaluation of antibodies for the radioimmunoassay of gastrin. Scandinavian Journal of Clinical and Laboratory Investigation, 30, 221-232.

Rehfeld, J. F., Stadil, F., and Vikelsöe, J. (1974). Immunoreactive gastrin components in human serum. Gut, 15, 102-111.

Stadil, F., and Rehfeld, J. F. (1972). Preparation of ${ }^{125} \mathrm{~J}$ labelled synthetic human gastrin I for radioimmunoanalysis. Scandinavian Journal of Clinical and Laboratory Investigation, 30, 361-368.

Stanley, M. D., Coalson, R. E., Grossman, M. I., and Johnson, L. R. (1972). Influence of secretin and pentagastrin on acid secretion and parietal cell number in rats. Gastroenterology, 63, 264-269.

Sutton, D. R., and Donaldson, R. M. (1975). Synthesis and secretion of protein and pepsinogen by rabbit gastric mucosa in organ culture. Gastroenterology, 69, 166-174.

Steenbeck, L., and Wolff, G. (1971). Histoautoradiographische Untersuchungen der menschlichen Magensschleimhaut bei chronischen Gastritis und Magenkarzinom. Archives für Geschwulstforschung, 38, 132-138.

Willems, G., and Vansteenkiste, Y. (1974). Resistance of the antral mucosa to the trophic effect of gastrin in the dog. Biologie et Gastroenterologie, 7, 237-240.

Willems, G., Vansteenkiste, Y., and Limbosch, J. M. (1972). Stimulating effect of gastrin on cell proliferation kinetics in canine fundic mucosa. Gastroenterology, 62, 583-589.

Willems, G., Vansteenkiste, Y., and Smets, P. (1971). Effects of food ingestion on the cell proliferation kinetics in the canine fundic mucosa. Gastroenterology, 61, 323-327.

Willems, G., Vansteenkiste, Y., and Smets, P. (1972). Cell proliferation in the mucosa of Heidenhain pouches after feeding in dogs. American Journal of Digestive Diseases, 17, 671-674. 